\title{
Postoperative subcutaneous emphysema: prevention and treatment
}

\author{
Joshil V. Lodhia, Sara Tenconi \\ Department of Cardio-thoracic Surgery, Northern General Hospital, Sheffield, UK \\ Contributions: (I) Conception and design: All authors; (II) Administrative support: None; (III) Provision of study materials or patients: None; (IV) \\ Collection and assembly of data: None; (V) Data analysis and interpretation: None; (VI) Manuscript writing: All authors; (VII) Final approval of \\ manuscript: All authors. \\ Correspondence to: Miss Sara Tenconi. Department of Cardio-thoracic Surgery, Chesterman Wing, Northern General Hospital, Sheffield, S5 7AU, \\ UK. Email: sara.tenconi@nhs.net.
}

\begin{abstract}
Post-operative subcutaneous (or surgical) emphysema (POSE) affects approximately six percent of patients undergoing thoracic surgery. Pre-operative forced expiratory volume in 1 second $\left(\mathrm{FEV}_{1}\right)$ and lung diffusion capacity for carbon monoxide (DLCO) poorer than $50 \%$ of predicted, the presence of adhesions and a post-operative air leak are predictive factors for post-operative subcutaneous emphysema. POSE leads to increased patient distress, dyspnoea, empyema and prolonged length of stay (LOS). The management of this condition should aim at ensuring that the lung is fully expanded through adequate drainage of the chest cavity, in order to expedite sealing of the parenchymal tear. This may require the use of low-pressure suction $\left(-20 \mathrm{cmH}_{2} \mathrm{O}\right)$ and pleurodesis techniques. Symptomatic relief can be achieved with sub-cutaneous drains or by applying negative pressure dressing [vacuum assisted closure (VAC) pump]. A small percentage of patients (approximately 1\%) require a further surgical procedure to control the air leak.
\end{abstract}

Keywords: Surgical emphysema; air leak; lung cancer; surgery

Received: 12 February 2020; Accepted: 23 March 2020; Published: 10 April 2021.

doi: $10.21037 /$ shc.2020.03.08

View this article at: http://dx.doi.org/10.21037/shc.2020.03.08

\section{Introduction}

Surgical emphysema or subcutaneous emphysema is air trapped within the subcutaneous tissues. It manifests with sudden swelling, dysphonia ("nasal voice"), sore throat and in more extensive cases dysphagia, pain and respiratory impairment. The causes of this condition can be broadly categorised into three groups: mucosal disruption of an airfilled structure (airways), soft tissues infection sustained by gas-forming organisms or lung alveolar rupture with visceral pleural tear. Although subcutaneous emphysema can be caused by blunt or penetrating trauma, iatrogenic airways damage or rarely infections, lung parenchymal injury is inherent in thoracic surgery and thus is not an uncommon postoperative finding (Figure 1). Cerfolio

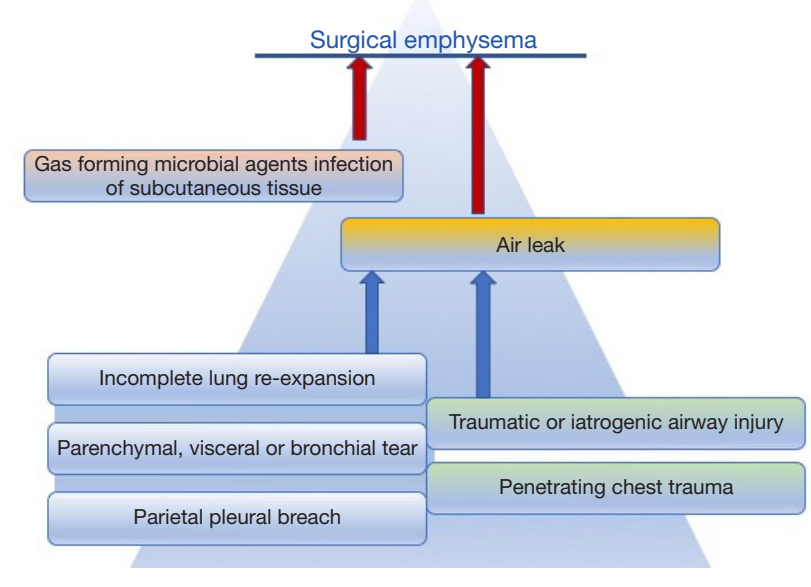

Figure 1 Aetiopathogenesis of surgical emphysema. 


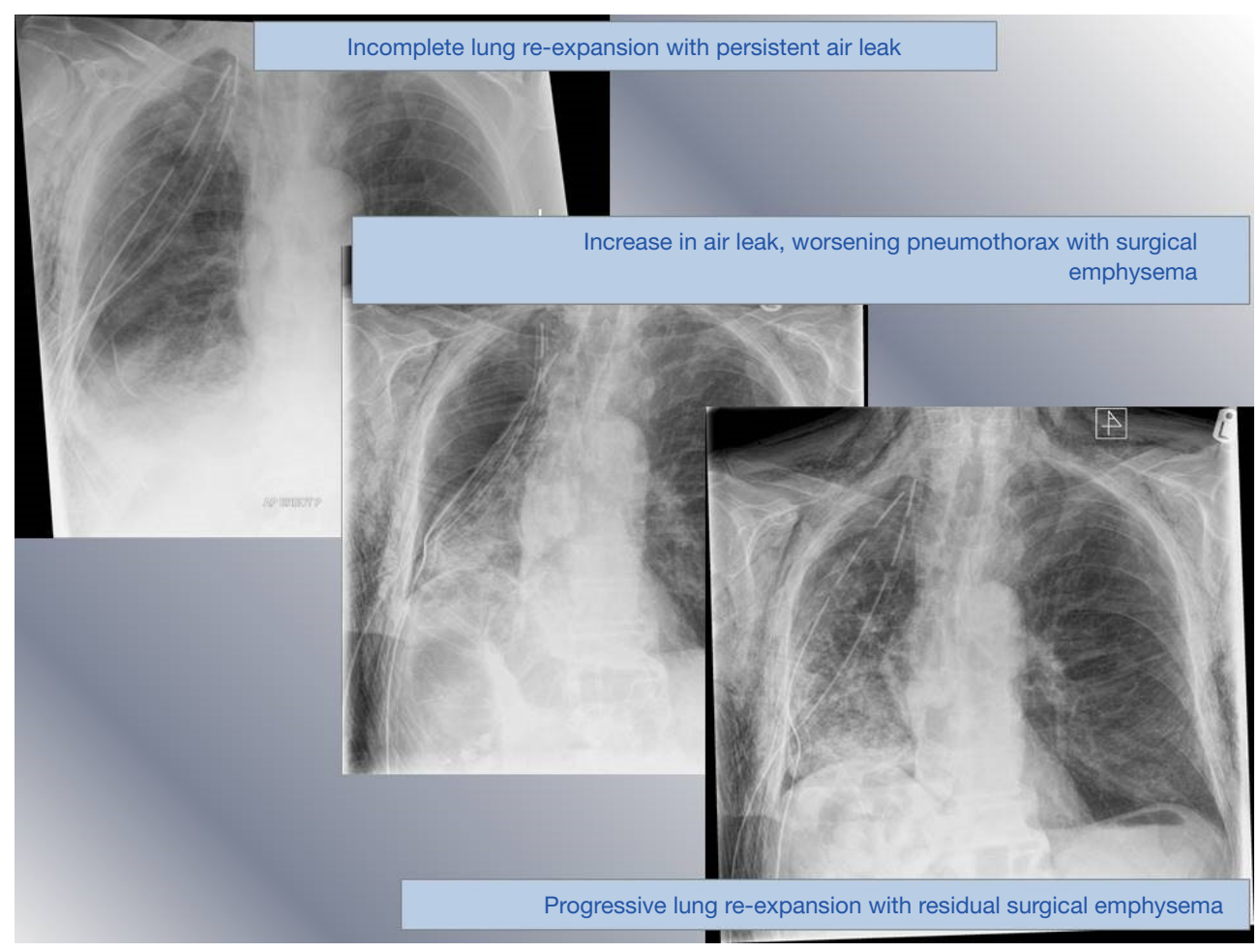

Figure 2 Surgical emphysema associated with prolonged air leak.

et al. found that $6.3 \%$ of patients undergoing thoracic surgery had clinically apparent surgical emphysema (1); however a minor degree of asymptomatic, localised subcutaneous emphysema can certainly be observed in a higher proportion of patients. Interestingly, not much relevance has been given to the subject in current literature.

This article will discuss the causes and preventative strategies of subcutaneous emphysema in the thoracic postoperative period. The main area of focus will be on the currently available management options for this condition.

\section{Aetiology}

Subcutaneous emphysema is defined as air presence in the subcutaneous tissues; it usually starts in the upper part of the body but could expand to virtually the whole body and into deeper soft tissues (2). It is generally regarded as a benign condition (3), however it can pose a significant amount of discomfort to the patient and in rarer cases it has been reported to cause high airway pressure, severe respiratory acidosis, pacemaker malfunction, airway compromise and be associated with tension phenomena, not to mention the risk of superimposed mediastinal infection, which in itself could be life threatening (4).

As the air within the subcutaneous space extends, it rises into the neck and face, fill the eye lids to a point where the patient may be unable to open their eyes, adding to their distress. Furthermore, the appearance of swelling can be disfiguring, alarming friends and family. Surgical emphysema in the post-operative period is often present in the setting of prolonged air leak (Figure 2); persistent air leak in itself increases the risk of empyema (5) and all these factors lead to an extended LOS. Aghajanzadeh et al. noted an average LOS of 16 days in these patients (2).

To generate post-operative subcutaneous emphysema there needs to be an air leak, associated with a breach in the pleura, the parenchyma or a bronchus. The nature of thoracic surgery requires the breach of the parietal pleura in order to gain access to the chest cavity. Visceral pleura is breached when releasing adhesions or when resecting lung parenchyma. The release of adhesions has been demonstrated to also increase the risk of post-operative air leaks $(1,6)$.

Furthermore, once the lung re-expands the negative intra-thoracic pressure could potentially attract air through the chest wall defect and into the surrounding tissue, 


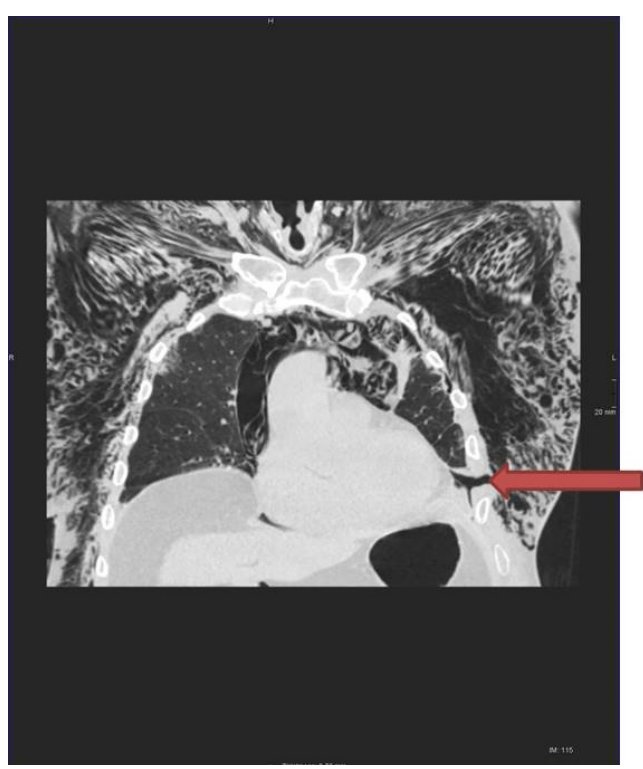

Figure 3 Chest wall defect and associated severe surgical emphysema.

therefore inadequate closure of the wound can exasperate this condition (Figure 3).

Intraoperative airways management can also cause surgical emphysema if the mucosa is interrupted. This is most likely to be damage to the posterior, membranous, wall of the trachea or bronchus. This will lead to a significant air leak, that is difficult to manage with drainage and can ultimately result in incomplete lung re-expansion and subcutaneous emphysema.

It is worth noting that, while the onset is usually sudden, re-absorption of subcutaneous emphysema can take several days or weeks and therefore it is important to reassure patients and families that it is likely to still be present on discharge.

\section{Prevention}

Despite its prevalence, there is little research into factors that can predict the development of this post-operative complication. Cerfolio et al. however, have demonstrated that a $\mathrm{FEV}_{1}$ or lung diffusion capacity for carbon monoxide (DLCO) of less than $50 \%$ increase the risk of post-operative subcutaneous emphysema (1).

Given that POSE leads to an increase morbidity and LOS, it is important to utilize prevention strategies. Ultimately, decreasing the risk of post-operative air leak will decrease the risk of POSE. Patients with severe
COPD, emphysema, smoking habit, corticosteroid treatments or diabetes are more likely to develop POSE, as these conditions are associated with increased or persistent air leak (7). For example, patients undergoing bullectomy or Lung Volume Reduction Surgery are more likely to have post-operative air leaks and subsequently develop subcutaneous emphysema. This is the result of a combination of incomplete or delayed lung re-expansion and parenchymal tear, due to extreme tissue fragility and hyper-expanded chest cavity.

\section{Intra-operative prevention}

The use of pericardial, polydioxanone or Teflon buttressed staplers can decrease the risk and duration of post-operative air leaks (8). Prior to completing the procedure, underwater testing can identify areas of air leak to be addressed. If such leak is noted, potential options are further resection of the culprit area, over-sawing of the parenchyma or use of additional lung sealants. There are many options for sealants on the market currently; according to a Cochrane review BioGlue (CryoLife, Kennesaw, US), TachoSil (Nycomed, Linz, Austria), PleuraSeal (Covidien, Copenhagan, Denmark), TissuePatch (Tissuemed, Leeds, UK), Evicel (OMRIX biopharmaceuticals S.A, RhodeSt-Genèse) and Tisseal (Baxter, Allerød, Denmark) have proven to be effective in improving control of air leak (9).

Before closing the chest, it is important to suction the airways to prevent subsequent collapse and facilitate full re-expansion of the lung to fill the pleural space. In fact, if there is a superficial area of leak, full lung re-expansion can increase the chance of sealing this area by occluding it through direct contact with the chest wall. On wound closure, ensuring that muscle is closed tightly and that there is no gap around the drain site is imperative.

\section{Perioperative prevention}

Early physiotherapy and mobilization in patients with incomplete lung re-expansion is also associated with faster recovery (10). ERAS protocols have proven to shorten the LOS without affecting re-admission rates, decrease complications and hospital costs $(11,12)$. Further to early physiotherapy, patients should have their pre-operative nutritional status assessed and supplements provided to those who are malnourished. Smoking should be stopped at least 4 weeks prior to surgery. Pre-operative sedatives should be avoided. In order to facilitate early mobilization, 


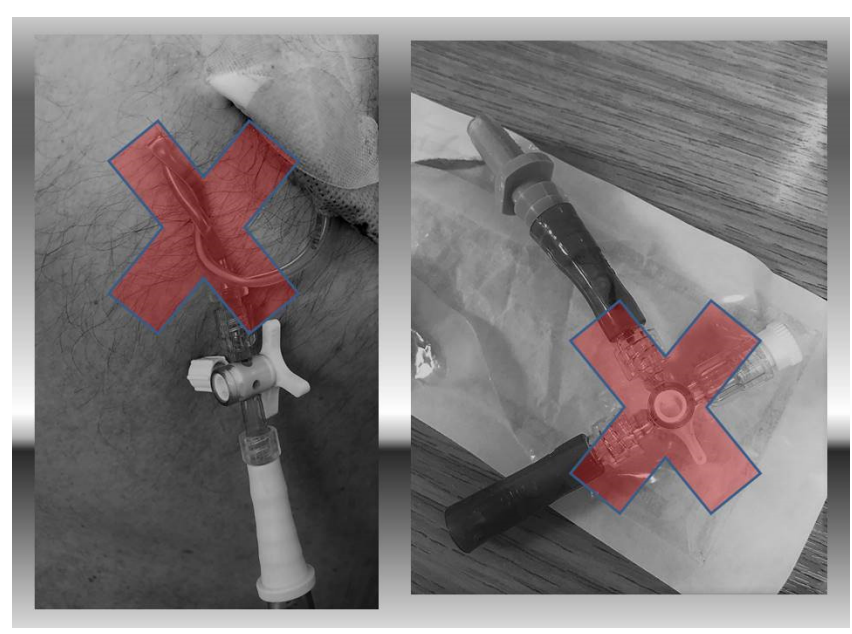

Figure 4 Small bore chest drain torsion and 3-way tap occlusion.

drains should be removed even if daily serous effusion is of high volume (450 mL/24 hours) (13). The number of drains positioned, the use of suction applied to chest drains and the use of digital drain systems have also been investigated in relation to the management of air leaks (14). For anatomical lung resections a single drain should be used to limit post-operative pain. The use of digital drains allows for protocolized removal of the drains and also gives the option of variable rates of low-pressure suction. All these factors should help patients mobilise earlier, increasing the chance of lung re-expansion and subsequent cessation of an air leak. There is no consensus on whether standard suction $\left(-20 \mathrm{cmH}_{2} \mathrm{O}\right)$ should be routinely applied to lung resections. In fact, it has been proven that low suction $\left(-2 \mathrm{cmH}_{2} \mathrm{O}\right)$ can reduce the duration of postoperative air leak and allow early drain removal, compared to higher suction $\left(-10 \mathrm{cmH}_{2} \mathrm{O}\right)(15)$. The size and number of drains is also variable according to preferences, with little or no evidence in support of different approaches, except the assumption of lesser pain associated with smaller drains. However, we do recommend that in case of big air leak and development of POSE adequate size drains (20 F or over) are used. This will prevent blockage or torsion. Bigger drains will also avoid the need for continue "flushing"; the use of a 3-way tap between the drain and the water seal is also not recommended, as it will generate a narrowing that can ultimately facilitate obstruction (Figure 4).

\section{Management}

The current management of POSE is focused on symptom relief as well as the identification and management of the underlying cause. We have created a treatment algorithm for the management of this condition (Figure 5).

\section{Release of superficial tension}

Once POSE has been identified, it is important to check if the lung is fully expanded and if the drains are working properly. The use of chest radiography or computed tomography (CT) helps to confirm and tracks the extent of the pneumothorax and emphysema.

If the lung is fully expanded and the surgical emphysema is not expanding, a conservative approach will most often be successful.

If the subcutaneous emphysema is extending, a twocentimetre infra-clavicular incision can be made under local anaesthetic with either a non-occlusive dressing or a negative pressure dressing to aid evacuation of air. Negative pressure dressings have the advantage of a sealed unit, decreasing the risk of contamination and wound infections. Furthermore, it decreases the risk of premature wound closure (Figure 6).

An alternative to this method is to insert a tunnelled chest drain under local anaesthetic in the subcutaneous space, to be connected to a water seal bottle. Suction is usually not indicated in this case, as it might cause the soft tissues to collapse around the drain holes, thus limiting the efficacy.

\section{Optimization of lung expansion}

If the lung is not fully expanded, it is important to confirm the presence of a well sited intercostal drain. All the drain holes need to be within the pleural space and confirmation that the drain is swinging or bubbling helps to verify its patency; digital drains system have alarms for clogged or blocked tubing. Additional chest drains, either surgical or image guided to tackle pockets of localised pneumothorax, should be positioned promptly to help lung re-expansion. Examination of the wound site needs to be performed to check that they are adequately sealed and that there is no air escaping around the drain site. Bronchoscopy should be considered if bronchopleural fistula or iatrogenic airways damage cannot be completely ruled out.

To encourage lung re-expansion, low pressure suction should be applied to the chest drain (approximately $-20 \mathrm{cmH}_{2} \mathrm{O}$ or $-2 \mathrm{kPa}$ ). If there is an air leak the re-expansion following suction may decrease the duration of the leak. There are 


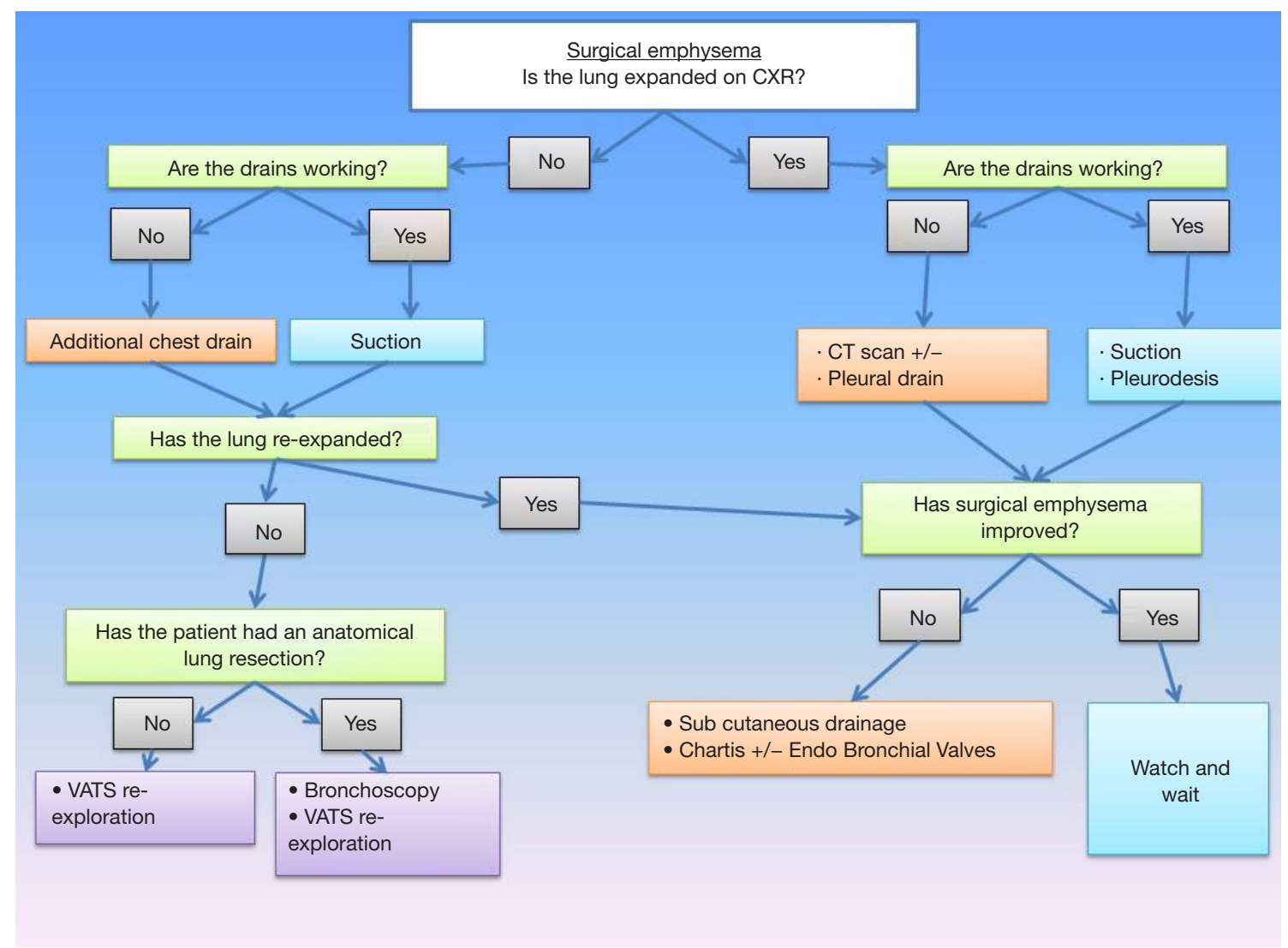

Figure 5 Management of post-operative surgical emphysema. CXR, chest X-ray; VATS, video-assisted thoracoscopic surgery.

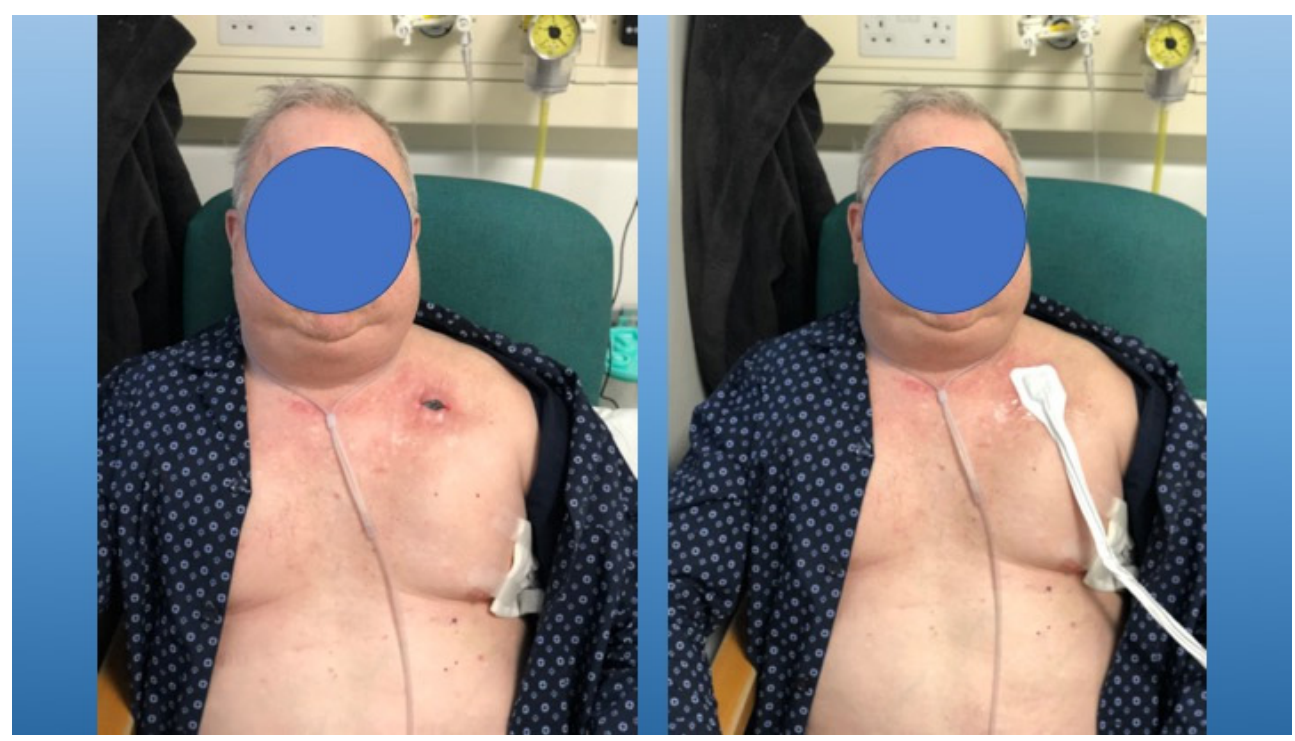

Figure 6 Two centimetres sub-clavicular incision with sponge dressing inserted (left). VAC pack applied (right). VAC, vacuum assisted closure. 


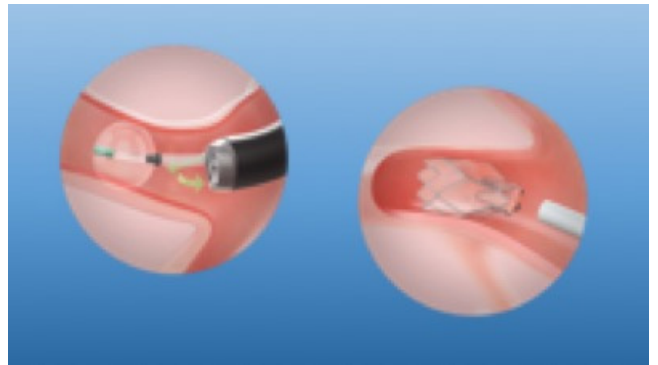

Figure 7 Chartis balloon for assessment of air leak and endobronchial Zephyr valve (Courtesy of Pulmonx Corporation, 700 Chesapeake Drive, Redwood City, CA 9406, United States).

various studies which have varying results with regards to the use of post-operative drain suction. A randomised control trial which placed post lung resection drains onto suction on day 1 compared to an underwater seal, demonstrated that by day 3 those with an underwater seal had less air leaks compared to the group on suction. Furthermore, those who crossed over from suction to the underwater system had an earlier resolution of the air leak (16). Similarly, Brunelli et al. showed a non-inferiority of nonsuction versus suction (17). On the other hand, Alphonso et al. showed no difference in air leak duration in the two groups (18).

Pleurodesis techniques should also been considered in order to minimise and prevent further complications such as POSE (19). Talc pleurodesis work by causing inflammation of the pleural leaflets, therefore full lung re-expansion is required for it to be beneficial. Blood pleurodesis can be considered when the lung fails to re-expand, when the clots might help sealing the parenchymal tear.

\section{Surgical repair}

Should conservative management fail, without signs of improvements (or even worsening) of the subcutaneous emphysema in the first 24 to 48 hours, return to theatre will allow to explore the lung surface, identify the point of leakage, seal it and re-position chest drains more effectively. The timing is very often patient's led, as the condition can be extremely distressful for some or reasonably well tolerated by others. Respiratory distress, cardiovascular instability or hypoxia due to underlying incomplete lung reexpansion will require immediate action. Similar attitude should be adopted if a bronchopleural fistula is suspected. Video-thoracoscopic approach is preferable to explore the pleural cavity and assess the need for parenchymal repair, further lung resection, drain re-positioning or to perform pleurodesis if required; bronchoscopy should be performed after induction and orotracheal intubation to plan further surgery and define the optimal approach for a bronchopleural fistula repair. Liaising with the anaesthetic team is important, as surgical emphysema of the glottis might complicate orotracheal intubation at this stage and positive pressure ventilation can increase the leakage and worsen the condition. Although there are only limited clinical reports in literature, there is support that spontaneous breathing in case of conservative treatment of tracheobronchial rupture is associated with the best outcome, therefore laryngeal masks airway (LMA) and sedation should be discussed (20).

On re-opening the chest, it is important to thoroughly assess all structures to identify the source of the leak. If the leak is from the bronchus, the options are primary repair with or without patch repair. Patch repairs can involve the use of intercostal muscle, latissimus dorsi, omentum, pectoralis major, rectus abdominis or serratus anterior (21).

If the leak is identified to originate from the lung parenchyma, the previously discussed options of further lung resection or the use of sealants can be considered at this stage. During this procedure it is also important to release any adhesions preventing full re-expansion of the lung. Return to theatre and the release of adhesions has been demonstrated to reduce subcutaneous emphysema and hospital stay (1) in a group of patient who had an early return to theatres if POSE persisted despite suction at $-40 \mathrm{cmH}_{2} \mathrm{O}$. Another option is to create a pleural tent: Brunelli et al. showed a decreased duration of air leak and a shorter LOS in patients that underwent a pleural tent at the same time as an upper lobectomy (22).

If the lung is mostly expanded and access to chest cavity might pose a risk the due to extensive pleuroparenchymal adhesions, the use of endobronchial valves have been described for treating air leaks (23). The procedure can be done under either general anaesthesia or deep sedation and requires a Chartis ${ }^{\circledR}$ balloon assessment to identify the lobar or the segmental bronchus feeding into the leakage (Figure 7). Once this has been identified, by inflating the balloon and blocking the air leak coming through the chest drain, one or more valves can be inserted. Distal collapse of the parenchyma, following valve insertion, will expedite sealing. However, residual space has been described to persist after valves insertion and valves removal should be considered after the air leak has settled and drains are out (24). 
There is no mention of extended need for antibiotic cover in patients with surgical emphysema. However, given that prolonged air leak and re-operation are associated with higher risk of empyema, patients who are at risk because of comorbidities or immuno-suppressant treatments or who require multiple surgeries should be closely monitored and given antibiotic cover if required.

\section{Summary}

Post-operative subcutaneous emphysema is a common complication following thoracic surgery. Predictive factors include pre-operative $\mathrm{FEV}_{1}$ and DLCO of less than $50 \%$, previous ipsilateral thoracotomy and other related risk of adhesions and the presence of a post-operative air leak. In high risk patients, the use of sealants, re-enforced staplers or the pre-emptive creation of a pleural tent may decrease the risk of POSE. Once POSE develops, the management should be aimed at ensuring lung expansion with the use of low-pressure suction. Symptomatic relief can be obtained expeditiously with the use of blow holes with negative pressure dressings. In a small percentage of patients, return to theatres maybe required to treat ongoing causes of air leaks.

\section{Acknowledgments}

Funding: None.

\section{Footnote}

Provenance and Peer Review: This article was commissioned by the Guest Editor (David Waller) for the series "Complications of Thoracic Surgery-aetiology, management and prevention" published in Shanghai Chest. The article has undergone external peer review.

Conflicts of Interest: Both authors have completed the ICMJE uniform disclosure form (available at http://dx.doi. org/10.21037/shc.2020.03.08). The series "Complications of Thoracic Surgery-aetiology, management and prevention" was commissioned by the editorial office without any funding or sponsorship. The authors have no other conflicts of interest to declare.

Ethical Statement: The authors are accountable for all aspects of the work in ensuring that questions related to the accuracy or integrity of any part of the work are appropriately investigated and resolved.
Open Access Statement: This is an Open Access article distributed in accordance with the Creative Commons Attribution-NonCommercial-NoDerivs 4.0 International License (CC BY-NC-ND 4.0), which permits the noncommercial replication and distribution of the article with the strict proviso that no changes or edits are made and the original work is properly cited (including links to both the formal publication through the relevant DOI and the license). See: https://creativecommons.org/licenses/by-nc-nd/4.0/.

\section{References}

1. Cerfolio RJ, Bryant AS, Maniscalco LM. Management of Subcutaneous Emphysema After Pulmonary Resection. Ann Thorac Surg 2008;85:1759-63; discussion 1764-5.

2. Aghajanzadeh M, Dehnadi A, Ebrahimi H, et al. Classification and Management of Subcutaneous Emphysema: a 10-Year Experience. Indian J Surg 2015;77:673-7.

3. Beck PL, Heitman SJ, Mody CH. Simple construction of a subcutaneous catheter for treatment of severe subcutaneous emphysema. Chest 2002;121:647-9.

4. Rydell JR, Jennings WK. Emergency cervical mediastinotomy for massive mediastinal emphysema. AMA Arch Surg 1955;70:647-53.

5. Brunelli A, Xiume F, Al Refai M, et al. Air leaks after lobectomy increases the risk of empyema but not of cardiopulmonary complications: a case-matched analysis. Chest 2006;130:1150-6.

6. Singhal S, Ferraris V, Bridges C, et al. Management of Alveolar Air Leaks After Pulmonary Resection. Ann Thorac Surg 2010;89:1327-35.

7. Dugan KC, Laxmann B, Murgu S, et al. Management of Persistent Air Leak. Chest 2017;152:417-23.

8. Stammberger U, Klepetko W, Stamatis G, et al. Buttressing the staple line in lung volume reduction surgery: A randomized three-center study. Ann Thorac Surg 2000;70:1820-5.

9. Serra-Mitjans M, Belda-Sanchis J, Rami-Porta R. Surgical sealant for preventing air leaks after pulmonary resections in patients with lung cancer. Cochrane Database Syst Rev 2005;(3):CD003051.

10. Medbery RL, Fernandez FG, Khullar OV. ERAS and patient reported outcomes in thoracic surgery: a review of current data. J Thorac Dis 2019;11:S976-S986.

11. Madani A, Fiore J, Wang Y et al. An enhanced recovery pathway reduces duration of stay and complications after open pulmonary lobectomy. Surgery 2015;158:899-908. 
12. Rogers LJ, Bleetman D, Messenger DE, et al. The impact of enhanced recovery after surgery (ERAS) protocol compliance on morbidity from resection for primary lung cancer. J Thorac Cardiovasc Surg 2018;155:1843-52.

13. Khandhar SJ, Schatz CL, Collins DT, et al. Thoracic enhanced recovery with ambulation after surgery: a 6-year experience. Eur J Cardiothorac Surg 2018;53:1192-8.

14. French DG, Plourde M, Henteleff H, et al. Optimal management of postoperative parenchymal air leaks. J Thorac Dis 2018;10:S3789-S3798.

15. Holbek BL, Christensen M, Hansen H, et al. The effects of low suction on digital drainage devices after lobectomy using video-assisted thoracoscopic surgery: a randomised controlled trial. Eur J Cardiothorac Surg 2019;5 5:673-81.

16. Cerfolio RJ, Bass C, Katholi CR. Prospective randomized trial compares suction versus water seal for air leaks. Ann Thorac Surg 2001;71:1613-7.

17. Brunelli A, Salati M, Pompili C. Regulated tailored suction vs. regulated seal: a prospective randomized trial on air leak duration. Eur J Cardiothorac Surg 2013;43:899-904.

18. Alphonso N, Tan C, Utley M. A prospective randomized controlled trial of suction versus non-suction to the

doi: $10.21037 /$ shc. 2020.03 .08

Cite this article as: Lodhia JV, Tenconi S. Postoperative subcutaneous emphysema: prevention and treatment. Shanghai Chest 2021;5:17. under-water seal drains following lung resection. Eur J Cardiothorac Surg 2005;27:391-4.

19. Liberman M, Muzikansky A, Wright C, et al. Incidence and risk factors of persistent air leak after major pulmonary resection and use of chemical pleurodesis. Ann Thorac Surg 2010;89:891-7; discussion 897-8.

20. Pota V, Sansone P, Fiorelli A, et al. Anesthetic consideration for airway management of patients undergoing endoscopic fibrin glue treatment of tracheobronchial rupture: a case series of three patients. Perioper Med (Lond) 2018;7:31.

21. Dal Agnol G, Vieira A, Oliveira R, et al. Surgical approaches for bronchopleural fistula. Shanghai Chest 2017;1:14.

22. Brunelli A, Al Refai M, Monteverde M, at al. Pleural tent after upper lobectomy- a randomized study of efficacy and duration of effect. Ann Thorac Surg 2002;74:1958-62.

23. Toma TP, Kon OM, Oldfield W, et al. Reduction of persistent air leak with endoscopic valve implants. Thorax 2007;62:830-3.

24. NICE. Endobronchial valve insertion to reduce lung volume in emphysema: Interventional procedures guidance [IPG600]. (2017). 